\title{
NARRATIVA FEMINISTA EN LOS CUENTOS DE LA CONDESA DE PARDO BAZÁN
}

\author{
María Elena Ojea Fernández \\ UNED. Orense
}

\section{RESUMEN}

Este artículo esboza el interés que sintió la Condesa de Pardo Bazán por todo lo relacionado con la condición femenina. Doña Emilia fue una gran defensora de la mujer. Los relatos cortos, antes que las ficciones largas, ejemplifican mejor lo que Pardo Bazán entendió como "problema femenino». En este artículo ofrecemos una prueba de la preocupación de la autora por la situación femenina. Asimismo vislumbramos la imagen que de la mujer pretendió transmitir.

Virginia Woolf (1981: 57), señala que cuando una mujer se pone a escribir una novela, nota que desea cambiar constantemente los valores establecidos, convertir en serio lo que a un hombre le parece insignificante, y en trivial lo que para el varón es importante. Este cambio de valores provoca, según Woolf, una radical diferencia entre literatura de hombre y literatura de mujer. La diferencia no está en los temas, sino en la actitud ante los mismos. Pero, con todo, el distanciamiento más radical estriba en que cada sexo se describe a sí mismo. Y por supuesto, de ahí surgen las diferencias en la trama, en los incidentes y en la selección de método y estilo. Por ejemplo, el siglo XIX es rico 
en novelas escritas por hombres con protagonistas femeninas. Destacan las adúlteras. Nos preguntamos qué tratamiento habría tenido este tema si fuese una mujer la autora de estas novelas.

Sea como fuese es muy difícil encontrar una verdadera autenticidad femenina. Woolf supo darse cuenta de las numerosas contradicciones que tuvieron que soportar las primeras escritoras decimonónicas, quienes no tuvieron más remedio que desechar los valores propios y acercarse a otros ajenos pero dominantes. En su opinión, tan sólo Emily Brontë y Jane Austen supieron mantenerse firmes y no hacer concesiones a las opiniones dominantes (BLANCO, 1991:21). Para Woolf, la escritora femenina ideal debe superar los condicionamientos del propio sexo, ser libre, tener conocimiento del mundo y libertad de movimientos. La escritura no sexista ha de liberarse del sexo, aunque no negarlo. Para ella las grandes mentes eran andróginas, por lo que esta convicción representaba una síntesis que superaba la exclusividad masculina y femenina. Sin embargo, Woolf tuvo también sus detractores. Toril Moi (MOI, 1995:21) señala a Elaine Showalter y a Patricia Stubbs como principales críticos. Showalter acusa a Woolf de querer huir del sexo abrazando la idea de la androginia. En su opinión, Woolf fracasa porque rechaza la necesidad fundamental del individuo de adoptar una identidad única e integrada. El feminismo de Elaine Showalter defendía como valor crucial esa identidad unitaria en oposición frontal al machismo tradicional que pretendía anularla. Por su parte Patricia Stubbs reprochó a Woolf que no intentase crear modelos nuevos de mujer, esto es, retratos veraces con los que el lector pudiera identificarse. Para Stubbs las novelas creadas - tanto por hombres como por mujeres- en el período comprendido entre 1880 y 1920 adolecen de una falta de representación totalizadora de la vida profesional y privada de las mujeres y, por tanto, resultan poco creibles.

Woolf se opuso al esencialismo metafísico que subyace bajo toda ideología machista. Woolf comprendió que el objetivo principal de la lucha feminista tenía que ser la destrucción de la oposición masculino/femenino. La escritora británica no se quiso encasillar en un estilo racional por lo que rompió con el lenguaje simbólico. Pero el orden simbólico es un orden machista y todo aquel que intentara trastocarlo se situaba en posición de rebeldía. De ahí los recelos que levantaba.

En fin, dicho esto, pretendemos saber si doña Emilia compartía los postulados de Virginia Woolf o si más bien esa postura estaba dentro de lo que críticos como Stubbs o Showalter apuntaban dentro de su línea feminista.

En el siglo XIX es notable la presencia de la mujer en la literatura. Naturalmente esta presencia femenina es un reflejo de la realidad social: la mayor proliferación se da en Francia; es allí donde empiezan las mujeres a organizar- 
se primero. Por lo que se refiere a España, podemos señalar que las mujeres ocupan el último lugar en cuanto a población activa femenina (LAFFITTE, 1964:354).

Según va avanzando el siglo, las cosas parecen cambiar de enfoque. La segunda mitad del siglo XIX se caracteriza por la ruptura de los sistemas tradicionales. El matrimonio y el estatismo de las clases sociales empiezan a ponerse en duda. El modelo de buena esposa y madre era el tradicional y el impuesto por el poder dominante. No obstante, con el Romanticismo se produce una relativa democratización sexual en el seno de los grupos liberales. Las cosas van variando pero la independencia femenina se complica por razones políticas: muchas mujeres se afilian a los grupos más revolucionarios con lo que el movimiento feminista pierde credibilidad en los medios más ortodoxos.

En la segunda mitad del siglo XIX, la emancipación de la mujer fue uno de los grandes temas a tratar. Nietzche decía que el mero hecho de que la mujer quisiera ser independiente era el peor desarrollo del afeamiento en Europa: «Se va volviendo cada vez más histérica y más incapaz de cumplir su función única y primera: la de dar a luz hijos robustos»'.

Según esta postura la mujer liberada es presentada como un ser patológico y anómalo. La mujer debe temer al hombre, ser modesta y sumisa. En fin, los pensamientos del filósofo alemán representaban claramente la actitud y el sentir general de la sociedad patriarcal de su tiempo.

Uno de los aspectos más interesantes de la novelística del pasado siglo es el hecho de presentar a la mujer dentro de un rígido arquetipo. Por ejemplo, uno de los tipos más frecuentes lo constituyó la adúltera. Flaubert, Tolstoi, Clarín ...y otros, presentaron a una mujer insatisfecha, triste consigo misma, una mujer para la que el matrimonio carecía de sentido. Su infelicidad perpetua y la impermeabilidad de las costumbres propiciaba la infidelidad matrimonial, presente tanto en el varón como en el ambiente. No se trata de un destino fatal, más bien de un destino impuesto por la sociedad y por ciertas cuestiones de honor. Pardo Bazán trata poco el tema del adulterio. Sus heroínas son mujeres que fracasan por culpa del poder patriarcal. Es éste el culpable de haber predispuesto distintos papeles que hombres y mujeres se ven obligados a cumplir. Precisamente esta cuestión tan polémica la trató la Condesa en varias ocasiones, una de ellas en un cuento que apareció en 1895 en La España Moderna con el título de Mujer. En este cuento se ataca y se critica la aceptación ciega de la noción del código del honor, que no sólo perjudica a las mujeres sino que

1 La cita del pensador alemán y en concreto de su libro Más allá del bien y del mal: Madrid, Alianza, 1982, ha sido tomada de La mujer insatisfecha, libro publicado en 1984 por la autora de origen lituano BIRUTE CIPLuauskaITE. 
complica la vida del varón al presuponérsele guardián de la honra femenina. Doña Emilia critica al hombre por la división de roles y por su comportamiento para con la mujer. De cualquier forma, hay un hecho curioso y es que en el relato que nos ocupa, Pardo Bazán hace aparecer en algunos personajes masculinos, aspectos propios del temperamento femenino. Por ejemplo, Alfonso es un ser pasivo, un rasgo que se considera innato a las mujeres. Sin embargo, Ana, la protagonista, es una mujer cuyo carácter se aleja de los estereotipos femeninos convencionales. Es fuerte y decidida, pero no está libre de prejuicios y difícilmente escapa a las normas socio-sexuales. Prueba de ello es que cuando se entera de que Alfonso no responde al ROL masculino asignado, cuando sabe que tiene miedo a morir en un duelo, entonces, se desilusiona profundamente. Como mujer prefiere un hombre fuerte que la proteja y la defienda.

El paisaje y las gentes de Galicia fueron una fuente constante de inspiración para la autora gallega. Para empezar, la mujer que aparece en los cuentos de Doña Emilia, es una hembra robusta acostumbrada a trabajos duros. La temible Aura Lebriña de Geórgicas constituye un buen ejemplo. Ella sola se vale para vengarse de la odiosa familia de los Raposo. Lo mismo podríamos decir de Mariniña en El molino, quien vence al matón de la comarca para asegurar la vida de Chinto, su amado, hombre débil y pusilánime (GONZÁLEZ ARIAS, 1997). Está claro que los términos se invierten y que los papeles sexuales serán temas muy manidos en la obra literaria de la Condesa. De todos modos, Pardo Bazán retrata no sólo el carácter resuelto, independiente y enérgico de las mujeres gallegas, sino también la situación de las mujeres maltratadas. En el famoso cuento El indulto se narra la historia de Antonia, una humilde asistenta que vive dominada por el terror a que regrese su marido -en prisión por el asesinato de la madre de ella- . El terror al indulto le acecha y la consume lentamente. Es una mujer maltratada que se alegra al recibir la noticia de la falsa muerte del marido y que desesperada ante el retorno del parricida acaba muriéndose de «muerte natural».La Pardo deja al descubierto el delirante estado de la pobre Antonia y nos brinda un retrato de primerísima actualidad.

«La hipocresía de la muerte natural no le asustaba; pero la espantaba solamente que volvía su marido». (Pardo Bazán, 1996: 53)

¿Muerto el criminal, en víspera del indulto, antes de cumplir el plazo de su castigo! Antonia, la asistenta alzó la cabeza y por primera vez se tiñeron sus mejillas de un sano color y se abrió la fuente de sus lágrimas. Lloraba de gozo, y nadie de los que la miraban se escandalizo. Ella era la indultada; y su alegría, justa. Las lágrimas se agolpaban a sus lagrimales, dilatándole el corazón, porque desde el crimen se había quedado cortada, es decir, sin llanto. Ahora respiraba anchamente, libre de su pesadilla. (Pardo Bazán, 1996: 58-59). 
Y el niño fue quien, gritando desesperadamente llamó al amanecer a las vecinas que encontraron a Antonia en la cama, extendida. como muerta. El médico vino aprisa, y declaró que vivía y la sangró y no logró sacarle gota de sangre. Falleció a las veinticuatro horas, de muerte natural y no tenía lesión alguna. El niño aseguraba que el hombre que había pasado allí la noche la llamó muchas veces al levantarse, y viendo que no respondía echó a correr como un loco. (Pardo Bazán, 1996: 63).

El cuento nos habla de las inquietudes feministas de la Condesa - sin duda su faceta más progresista - al mostrar la mísera situación de la mujer. El relato deja bien patente cómo el terror al maltrato físico acaba por enajenar a la pobre asistenta que muere irremediablemente sin que nadie pueda evitarlo. Deja asimismo al descubierto la benevolencia de la justicia con el varón quien puede permitirse atemorizar a la mujer sin recibir castigo alguno.

—QQué leyes, divino Señor de los cielos! ¿Así los bribones que las hacen las aguantaran! — clamaba indignado el coro- ¿Y no habrá algún remedio mujer, no habrá algún remedio?

-Dicen que nos podemos separar... después de una cosa que llaman divorcio.

- ¿Y qué es divorcio, mujer?

-Un pleito muy largo.

Todas dejaron caer los brazos con desaliento; los pleitos no acaban nunca, y peor aún si se acaban, porque los pierde siempre el inocente y el pobre.

-Y para eso —añadió la asistenta - tenía yo que probar que mi marido me daba maltrato.

- ¡Aquí de Dios! ¿Pues aquel tigre no le había matado a la madre? ¿Eso no era maltrato?

-Pero como nadie la oyó ... Dice el abogado que se quieren pruebas claras... (Pardo Bazán, 1996: 53).

No obstante, también destaca la solidaridad entre las mujeres, un verdadero canto a la esperanza, pues deja entrever Doña Emilia que sólo de este modo se puede vencer al agresor.

«Y como no le permitía el estado de su bolsillo pagar ama, las mujeres del barrio que tenían niños de pecho dieron de mamar por turno a la criatura». (Pardo Bazán, 1996: 53).

Una buena moza, casada con un guardia civil, ofreció enviar a su marido para que le metiese miedo al picarón; otra, resuelta y morena, 
se brindó a quedarse todas las noches a dormir en casa de la asistenta. En suma: tales y tantas fueron las muestras de interés de la vecindad que Antonia se resolvió a intentar algo, y que sin levantar la sesión, acórdose consultar a un juriconsulto, a ver qué recetaba. (Pardo Bazán, 1996: 55).

Se armó una especie de motín. Había mujeres determinadas a hacer, decían ellas, una exposición al mismísimo rey, pidiendo contraindulto. Y, por turno, dormían en casa de la asistenta, para que la pobre mujer pudiese consultar el sueño. (Pardo Bazán, 1996: 56).

Y cómo no, los errores de la justicia, que en modo alguno favorecen a la víctima.

Cuando Antonia volvió de la consulta, más pálida que de costumbre, de cada tenducho y de cada cuarto de baño bajo salían mujeres en pelo a preguntarle noticias, y se oían exclamaciones de terror. ¿La ley, en vez de protegerla, obligaba a la víctima a vivir bajo el mismo techo, maritalmente con el asesino! (Pardo Bazán, 1996: 55).

Los temas de muchos de los relatos breves de doña Emilia son de gran actualidad y muestran la honda preocupación que sintió la Condesa por el destino de la mujer. Ciertamente el caso de Antonia fue verídico, pero el testimonio novelado de Pardo Bazán es una defensa a ultranza de los derechos de las mujeres. De hecho, las palabras de la Condesa al tener conocimiento del suceso son suficientemente explicativas:

"La situación exactamente como la pinto se da en La Coruña. Pocas cosas he escrito con menos tranquilidad y aquel reposo que requiere el arte. La consideración de tan atroz suceso me tenía acongojada" ${ }^{2}$.

La insuficiencia de las leyes para proteger a la víctima son también el tema de El silencio en donde un hombre celoso mata a su mujer y la entierra, evadiéndose de la justicia gracias a la emigración. Por su parte, El vampiro, narra la historia de un indiano que se casa con una muchacha joven. Al cabo de un tiempo la muchacha enferma y muere, mientras él rejuvenece.

2 La cita procede de una carta que PARDO BAZÁn dirigió a NARCIS Oller y que data de Julio de 1886. La recoge Francisca GOnzález Arias en su artículo sobre la poética de Galicia en los cuentos de la Condesa. Procede asimismo de los ESTUDIOS SOBRE EMILIA PARDO BAZÁN, In Memoriam Maurice Hemingway.Editado por José M. González Herrán. Universidad de Santiago de Compostela, 1997, p. 161. 
En El encaje roto, la protagonista rechaza al novio ante el altar. Doña Emilia hace gala de toda su lucidez al criticar la poca libertad de las solteras al elegir marido:

Ya sabe usted que mi boda con Bernardo de Meneses parecía reunir todas las garantías y condiciones de la felicidad. Además, confieso que mi novio me gustaba mucho, más que ningún hombre de los que conocía y conozco, creo que estaba enamorada de él. Lo único que sentía era no poder estudiar su carácter: algunas personas le juzgaban violento; pero yo le veía siempre contés, blando como un guante. Y recelaba que adoptase apariencias destinadas a engañarme y a encubrir una fiera y avinagrada condición. Maldecía yo mil veces la sujeción de la mujer soltera, para la cual es imposible seguir los pasos de su novio, ahondar en la realidad y obtener informes leales, sinceros hasta la crudeza, -los únicos que me tranquilizarían-. (Pardo Bazán, 1990: 332-33 .T.I).

La cuentística de doña Emilia aborda dos tipos femeninos que se entremezclan sucesivamente: la mujer con complejos de inferioridad y la mujer fuerte. Debemos hacer notar que el primero es el más frecuente. El segundo es un deseo, un modelo positivo femenino que la Condesa ansiaba y con el que también probó suerte en sus relatos largos.

Una de las características más relevantes de los relatos feministas de doña Emilia estriba en la propia composición de los mismos: existen cuentos en los que la voz del narrador lo ocupa todo, esto es, se presenta como un hecho y la figura del narrador opina, transmite los pensamientos del resto de los personajes y da el veredicto final. Otras, en cambio, presentan el hecho por boca de algún personaje, -incluido el protagonista-, permitiéndole que sea él quien dé la versión de los hechos. Los primeros permiten vislumbrar las ideas de nuestra autora; los segundos dejan el juicio al lector.

En relación a los primeros estaría Piña, uno de los cuentos en donde Pardo expone claramente sus ideas acerca de la explotación femenina y deja escapar su vehemente sentido crítico:

¿Estaría aquel galán empapado de las teorías de Luis Vives, fray Luis De León y otros pensadores que consideran a la hembra creada exclusivamente para el fin de cooperar a la mayor conveniencia, decoro, orgullo, poderío y satisfacción de los caprichos del macho? ¿Se habría propuesto llevar a la práctica el irónico mandamiento de la musa popular, que dice:

Tratarás a tu mujer

como mula de alquiler...(Pardo Bazán, 1990: 170 .T.I) 
¿Miedo?, ¿por qué? he aquí el problema que preocupaba, cuando me ponía a reflexionar en la suerte de la maltratada cubanita. Su marido, por mejor decir, su tirano, era de la misma estatura que ella; ni tenía más fuerza, ni más agilidad, ni más viveza, ni dientes más agudos, ni nada, en fin, sobre qué fundar su despotismo. ¿En qué consistía el intríngulis? ¿Qué influjo moral, qué soberanía posee el sexo masculino sobre el femenino, que así lo subyuga y así lo reduce, sin oposición ni resistencia, al papel de pasividad obediente y resignada, a la aceptación del martirio? (Pardo Bazán, 1990: 171 .T.I).

Como vemos, el sentido crítico está completamente aguzado en estos párrafos en los que doña Emilia da rienda suelta a sus ideas sobre la culpabilidad de la sociedad en el destino de la mujer. El triste final del animalito es una clara imagen de lo que el mundo patriarcal consiente en hacer con las mujeres. $\mathrm{Al}$ igual que Piña, muchas féminas se ven condenadas a arrastrar una existencia infame, obteniendo como única recompensa el sentimentalismo más trivial. Por ello quizás al final del cuento, una vez que el pobre animal aparece medio muerto, reaparece el carácter enérgico de la Condesa que señala:

«-Yo también quería llorar por la mona. ¡Pero no puedo!» (Pardo Bazán, 1990: 173 .T.I).

En la misma línea que el relato anterior situamos Cuento primitivo, un cuento en el que la autora emprende una reescritura del mito bíblico de la Creación. El hecho de que Eva sea creada de la costilla de Adán posibilita la facultad de éste de sentirse superior, al tiempo que la mujer pierde su «sustancialidad» propia y pertenece al varón. (HILLS, 1997: 22).

Lo importante de este cuento es señalar el legado psicológico que el mito genesíaco ha dejado en las mujeres, lo que en definitiva las ha perjudicado mucho ya que les hizo creer que son inferiores al hombre y lo que es peor, las ha privado de su propia estima:

El caso es que, a fuerza de oírlo, también Eva llegó a creerlo; se reconoció culpada y perdió la memoria de su origen, no atreviéndose ya a afirmar que era la misma sustancia que el hombre, ni mejor ni peor, sino un poco más fina. (Pardo Bazán, 1990:196 .T.I).

El sentimiento de culpa aparece también en La culpable. En este relato se cuenta la historia de una mujer que se muere de pena y de vergüenza. Las apariencias externas son vitales (especialmente para las familias acomodadas) y la pobre Elisa cometió un gravisimo e imperdonable error: escaparse con su marido an- 
tes de que éste lo fuera y pasar en su compañía veinticuatro horas de tren ... La familia se tomó el escándalo a pecho, tanto que cuando la madre se refería a Elisa suspiraba como si se hubiese muerto y el padre jamás volvió a pronunciar su nombre. Ante esta situación, Elisa se propone ser mujer de bien; se encierra en casa, no sale sola, vive con austeridad, es tiema y solícita con el marido ... hasta que cae enferma. Antes de morir se dirige al esposo para pedirle perdón. Resulta curioso observar como Elisa se culpa de una acción premeditada por su pretendiente, quien sabedor de la oposición de la familia de ella se aseguró así la presa de la acaudalada muchacha:

Con los ojos vidriosos de lágrimas Elisa pidió que viniese Adolfo, y así que le vio a su cabecera, echándole los brazos al cuello murmuró a su oído: «Alma mía, mi bien, ya sé que no tengo derecho ninguno a pedirte que... no te vuelvas a casar .... pero al menos... mira en esta hora solemne... perdóname de veras aquello... y no me olvides así... tan pronto... tan pronto... ».

Adolfo no contestó; no obstante, le pareció natural inclinarse y besarla... Y la culpable, dejando caer la cabeza sobre la almohada, expiró contenta. (Pardo Bazán, 1990: 304 .T.I).

La censura de la sociedad refleja un código moral que estipula que la mujer ha de ser de conducta intachable. La honra femenina no puede quedar en entredicho. Y como el hombre es el guardián del honor, toda falta de la mujer repercute en él. La reacción masculina ante los errores femeninos es virulenta y desproporcionada. Doña Emilia reprocha esa actitud y sus relatos cortos son buena prueba de ello. En una línea semejante al relato anterior se sitúan Tío Terrones y Las medias rojas (PARDO BAZÁN, 1975). La única diferencia con el relato de La culpable estriba en la reacción femenina ante la injusticia. Elisa se siente culpable y se martiriza hasta morir. Mientras, las protagonistas de Tío... y Las medias... intentan luchar y no darse por vencidas, aunque de una manera u otra no lo consiguen.

En Tio Terrones la Condesa relata el castigo ejemplar que el viejo Crispín Terrones propina a su hija. Al parecer, en el pueblo de la Montonera, se habló más del castigo del padre que del desliz de la hija. No era para menos dada la magnitud de la paliza:

Al saber el desliz de la muchacha, su padre había empezado por aplicarle una tremenda paliza con la vara de taray - la de apalear la capa por miedo a la polilla--, hecho lo cual, la maldijo solemnemente, como quien exorciza a un energúmeno y al fin, después de entregarle un mezquino hatillo y treinta reales, la sacó fuera de la casa, fulminando en voz alta la sentencia: 
-Vete a donde quieras, que mi puerta no has de atravesarla más en tu vida. Tío Terrones: 101.

La muchacha es maldecida por el padre y condenada al ostracismo. Petronila, que así se llama, simboliza a la mujer culpable que baja la cabeza y acepta su sino. El padre, con su mezquino proceder, encarna al poder patriarcal que condena, abusa y dispone la vida de las mujeres a su antojo. Sin embargo, no todo le ha ido mal a Petronila y con los años consigue progresar, eso sí, de forma oscura. De esto se entera la hermana menor, que movida por la codicia consigue contagiar al padre. Al final, el dinero toma la figura del honor y Zoila con el consentimiento de su progenitor decide asegurarse del paradero de la «maldita».

La tinta con que yo le escriba a esa pindonga, nosa fabricao ni sa fabricar, mujer.

Antes que Zoila, aturdida, opusiese impetuosa réplica, sin dar tiempo a que abriese la boca, a que respirase, Terrones se detuvo un momento y masculló sin transición de tono:

-Ahora, si tú quiés escribir... Hija, no digo... Tú, es otra cosa. $\mathrm{Pa}$ eso has io a la escuela y haces ese letruz tan reondi, que ino pice sino que estudiabas el oficio de mimorialista!. Tío Terrones: 106

Al lado de la mujer que ha cometido deslices imperdonables para la sociedad, nos encontramos con la que es víctima de la maledicencia masculina. Un ejemplo claro lo tenemos en La flor seca (PARDO BAZÁN, 1990 .T.I). El relato comienza cuando el señor conde de Acerolo revisa el gabinete de su difunta esposa. De repente encuentra un escondrijo que contiene una bolsita de raso, y dentro, en un envoltorio diminuto, tres flores amarillas. Sobre las hojas hay escrita una fecha detallada: año, mes, día y hora. El efecto que este hallazgo produce en el conde es inmediato. Empieza a romperlo todo, da puntapiés a los muebles y busca en vano una prueba de la potencial infidelidad de su esposa. Rendido, pregunta a los criados y es precisamente uno de ellos quien le saca de dudas. Aquella fecha que tanto le inquietaba delataba una infidelidad, sí, pero no de su mujer, sino de él mismo.

Lo que hizo la señora, no lo sé...; pero ese es un día en que tengo muy presente lo que hizo vuestra excelencia... Porque justamente... vamos...

-A ver... ¿qué justamente es éste? ¿Qué hice yo ese día?

- ¿Quiere el señor que se lo diga?

- ¿Hablo chino? Contesta a escape. 
- víspera pasó vuestra excelencia la noche fuera... ¡una casualidad! porque el señor no solía pasar fuera muchas... Le llevo el coche... ya sabe vuestra excelencia... al barrio... Y para que la señora no maliciase nada vine yo a contarle que el señor estaba en la Venta de la Rubia corriendo liebres, y hasta muy tarde no volvería... Volvió su excelencia pasada la hora de comer; pero la señora se había retirado ya.

No chistó el conde y el criado hizo mutis discretamente. La flor seca: 206.

Nuestra autora deja al descubierto el carácter manipulador y desconfiado del conde al presuponer un desliz en la difunta dama. Debemos señalar que la mezquindad, la ruindad y el complejo de superioridad masculinos aparecen con mucha frecuencia en los relatos de la Condesa, quien culpa al varón del descrédito social que padece la mujer.

Por su parte, el cuento de Las medias rojas, constituye uno de los relatos más estremecedores en cuanto a maltrato y vejación del hombre para con la mujer. La joven Ildara quiere procurarse una vida mejor. Planea emigrar. El padre, cansado de una vida de labor, indiferente a esperanzas tardías, no quiere marcharse. Pretende además que la hija se quede con él. En cuanto la muchacha tiene edad suficiente trama la posibilidad de aventurarse a ese otro mundo que tanto la ilusiona. El padre la descubre, y cegado por la ira la maltrata sin compasión:

- Ya te cansaste de andar descalza de pies y piernas, como las mujeres de bien, ¿eh, condenada? ¿Llevó medias alguna vez tu madre? ¿Peinóse como tú, que siempre estás dale que tienes con el cacho del espejo? Toma, para que te acuerdes...

Y con el cerrado puño hirió primero la cabeza, luego el rostro, apartando las medrosas manecitas, de forma no alterada aún por el trabajo, con que se escudaba Ildara, trémula. El cachete más violento cayó sobre un ojo, y la rapaza vio, como un cielo estrellado, miles de puntos brillantes envueltos en una radiación de intensos coloridos sobre un negro terciopeloso. Luego, el labrador aporreó la nariz, los carrillos. Fue un instante de furor, en que sin escrúpulo la hubiese matado, antes que verla marchar, dejándole a él solo, viudo, casi imposibilitado de cultivar la tierra que llevaba en arriendo. que fecundó con sudores tantos años, a la cual profesaba un cariño maquinal, absurdo. Cesó al fin de pegar: Ildara, aturdida de espanto, ya no chillaba siquiera. Las medias rojas: 146.

Como podemos apreciar las similitudes de este relato con Tristana de Pérez Galdós, son, a nuestro juicio, muy grandes y significativas. Ildara y Trista- 
na, son víctimas del poder patriarcal, desempeñado, bien por el padre, bien por el marido. El resultado es el mismo: la anulación total de la autoestima femenina y la imposibilidad de realizarse por sí mismas. Tristana acaba coja; Ildara tuerta. No hay futuro para ellas.

Salió fuera, silenciosa, y en el regato próximo se lavó la sangre. Un diente bonito, juvenil, le quedó en la mano. Del ojo lastimado no veía.

Como el médico, consultado tarde y de mala gana, según es uso de labriegos, habló de un desprendimiento de la retina, cosa que no entendió la muchacha pero que consistía ... en quedarse tuerta.

Y nunca más el barco la recibió en sus concavidades para llevarla hasta nuevos horizontes de holganza y lujo. Los que allá vayan han de ir sanos, válidos, y las mujeres, con sus ojos alumbrando y su dentadura completa... Las medias rojas: 146-47.

El tema del honor, ya tratado anteriormente en $M$ ujer, vuelve a aparecer en ¿Justicia? (PARDO BAZÁN, 1990 .T.I). En este caso, por motivos distintos. Don Pablo Roldán, casado con una dama elegante, bella y principal, acostumbra a alardear de la honestidad de su mujer. Sin embargo, el matrimonio oculta alguna grieta, algún desajuste que pronto saldrá a la luz de la manera más insospechada. Mientras asisten a una reunión en casa de una dama adinerada, la señora de Roldán repara en la belleza de un hilo de perlas. Es un buen motivo para que su amante, allí presente, se acerque a ella. Su marido que lo ha visto todo, roba el collar y anónimamente delata a su mujer. La esposa va a presidio por un delito que no cometió. La explicación de Roldán no deja lugar a dudas sobre la importancia de las apariencias. El honor es sagrado y quien lo transgrede debe expiar la culpa. Las explicaciones del marido dejan al descubierto su verdadero carácter. Doña Emilia, muy conocedora de las debilidades humanas, muestra en la reacción del hombre la falta de comprensión y el odio profundo de quien es incapaz de perdonar y se regocija en la venganza.

- No intervengas. ¡Paso a la justicia, paso!... Dejó de amarme, y no me creí con derecho ni a la queja: quiso a otro, y únicamente le rogué que no me entregase a la risa del mundo... ¡Y Ya sabes como atendió mi ruego... ya lo sabes! Antes que consiguiese ridiculizarme, la infamé. ¡Los medios fueron malos, pero... se lo tenía advertido! Si tú eres de los que creen que la venganza pertenece a Dios, apártate de mí, porque no nos entendemos, amor, odio y venganza... ¿ ¿ónde habrá nada más humano? ¿Justicia?: 300-301. 
La desigualdad socio-moral entre los sexos es un aspecto clave en la cuentística de doña Emilia. El adulterio no es lo mismo si lo comete un hombre que si lo comete una mujer. El señor Roldán actúa de esta forma porque la sociedad se lo permite. A las mujeres no se les reconoce el derecho al adulterio y, de cualquier modo, el marido tiene siempre derecho a represalia.

Aquí, como en otros casos, - Madame Bovary o La Regenta-, la condena es sin piedad.

La mentalidad patriarcal consideraba que la mujer era una cosa, un ser distinto al hombre; por consiguiente, su comportamiento debía ser distinto también. Así se lo hace llegar el padre Incienso a Amelia en el relato La novia fiel (PARDO BAZÁN, 1990, T.I). La joven, cansada de esperar diez años y ante la infidelidad de su prometido, decide romper el compromiso ante el estupor del novio, la familia y la sociedad en general. Aun cuando es una mujer humillada es también singular pues reconoce sus debilidades. Para contener sus pasiones sexuales, tanto tiempo reprimidas, emplea todo el recato y el sentido del honor que le enseñaron en la niñez. Y de alguna forma, este último es el que le guía a la hora de tomar su insólita decisión:

«-¡Padre —exclamó la joven-, créame usted pues hablo con Dios! ¡Le quería..., le quiero... y por lo mismo... padre! ¡Si no le dejo... le imito! ¡Yo también!». La novia fiel: 307

Los sentimientos de culpabilidad e inferioridad conducen a la mujer hacia un castigo propio. En el cuento anterior vemos clara la influencia de la ideología católica. La mujer que no es casta ha de emprender una lucha interminable por ganar acceso al orden patriarcal. Esa lucha, mantiene Kristeva, asume la forma de mortificación y culpabilidad, culminando con el masoquismo (HILLS, 1997: 175). La mera insinuación de impropiedad deja a la mujer desnuda y marcada para siempre. La reacción de Amelia reviste, por un lado, ribetes de religiosidad extrema; por otro, responde a la desigualdad con que la sociedad contempla las acciones de hombres y mujeres. A ellas se les exige que sean puras y castas hasta la extenuación. Al hombre se le perdonan las ligerezas, determinando que es algo normal y propio de su sexo.

La marginalidad femenina se repite con el tópico del encierro como medida de prevención. El ejemplo más claro lo tenemos en La niña mártir (PARDO BAZÁN, 1990.T.I).

Desde su nacimiento, la pequeña vive el mundo a través de la ventana. Sus padres le prohíben salir de casa temiendo que algo le pase. Las intenciones de los padres, pretendiendo ser buenas acaban siendo insensatas, pues debilitan la salud de la hija que termina muriendo. Lo mismo podemos decir de Cuento so- 
ñado (PARDO BAZÁN,1990 .T.I). Un rey fosco y muy caviloso obliga a vivir reclusa a su hija. La muchacha está prisionera en un torreón sombrío. Vigilada día y noche por centinelas armados, la joven sueña con traspasar los muros de su prisión. A diferencia de otros cuentos, la marginación de la princesa dimana del deseo de proteger a la amada — no de la venganza o de la condenación pública-. El poder masculino pretende con esa actitud no sólo proteger a la mujer sino mantener viva esa imagen idealizada de lo femenino. El mundo femenino se asemeja así al ambiente irreal de la niñez y de los cuentos de hadas. En la niña y en la princesa vemos el símbolo de la mujer burguesa, alienada, pasiva, que mira el mundo sin participar en él, es decir, al margen de la historia.

... Silencio y soledad alrededor de la torre, silencio y soledad dentro de ella. Tal era la suerte de la pobre doncellita, condenada a la eterna contemplación del cielo y del bosque, y del río caudaloso que serpenteaba lamiendo los muros del recinto. Cuento soñado: 310 .

No obstante, la cuentística de doña Emilia ofrece un modelo femenino positivo: la mujer fuerte. La autora recurre a una mujer de gran fortaleza física o mental, o con una hábil combinación de ambas. Pretende destacar que existen mujeres que demuestran un valor poco común. En general, ese arquetipo femenino lo localiza la Pardo en su Galicia natal, entre la gente campesina, que lleva una vida dura, pero no marginal. Las mujeres fuertes de los relatos de la Condesa están en perpetua unión con la naturaleza. Su caracterización nos sugiere un orden femenino más intuitivo y primitivo. Nos recuerda a civilizaciones basadas en el sistema matriarcal. Se alaba a la mujer de campo, capaz de superarse en situaciones límite. No hay, sin embargo, una reivindicación del campo mismo. En ese mundo difícil emerge el personaje de La Mayorazga de Bouzas (PARDO BAZÁN, 1975). Localizada la acción en los límites de El Bierzo, allá en las profundidades de El Barco de Valdeorras, una joven muchacha se cría gozando de una salvaje libertad. No nos olvidemos que Bouzas pertenece a la Galicia primitiva, como se nos recuerda al inicio del relato. La heredera, montada a caballo al estilo masculino, trabajaba duramente cargando el tojo, y en ocasiones hasta dobló el pulso y tumbó a algún gañán o mozo de labranza. No obstante, se nos recuerda que, pese a las apariencias de dureza y primitivismo, éste no llegaba a límites preocupantes. Quizás influye su condición social. Después de todo, ella era hija de don Remigio Padrón de las Bouzas, todo un honrado propietario:

Católica a machamartillo, oía su misa diaria en verano como en invierno, guiaba por las tardes el rosario, daba cuanta limosna podía. 
Su democrática familiaridad con los labriegos procedía de un instinto de régimen patriarcal, en que iba envuelta la idea de pertenecer a otra raza superior, y precisamente en la convicción de que aquellas gentes «no eran como ella», hasta el extremo de sentarse a su mesa, un día sí y otro también, dando ejemplo de frugalidad... La Mayorazga de Bouzas: 45.

A los veintidós años su padre la casa con el hijo de un amigo, un poco afeminado al que cuida y mima con pasión maternal. Cuando se entera de que su marido le es infiel con una costurera, la Mayorazga sólo piensa en salvar su matrimonio y trama una venganza implacable contra su rival: rapta a la joven, la lleva a las montañas y le corta las orejas. Este acto violento no parece desatar feroces críticas en el narrador. Antes al contrario, alecciona al lector hacia la simpatía por la mujer engañada que salva su unión, que sólo desea tener hijos y cuya venganza viene motivada por el dolor de la traición. La costurera no es retratada como víctima. Veámoslo:

La Mayorazga preguntó con voz ronca y grave:

- ¿Fue mi marido quien te regaló esos aretes?

- Sí - respondieron los ojos de víbora.

-Pues yo te corto las orejas - sentenció la Mayorazga extendiendo la mano. Y Amaro, que no era ni manco ni sordo, sacó su navajita corta, la abrió con los dientes, la esgrimió ... Oyóse un aullido largo, pavoroso, de agonía, luego, otro y sordos gemidos... [...]

De la costurera bonita, se sabe que no apareció nunca en público sin llevar un pañuelo muy pegado a la cara. De la Mayorazga que al otro año tuvo un muñeco. De Camilo Balboa, que no le jugó más picardías a su mujer. La Mayorazga de Bouzas: 57.

Como vemos, al final todo se arregla. La personalidad y la autoridad de la Mayorazga lo hacen posible. Es de hacer notar que al año siguiente el matrimonio tiene un bebé. Este hecho refuerza la valoración favorable de la Mayorazga. Para doña Emilia, la misión más noble de la mujer es la maternidad. En efecto, en su obra apreciamos como la Pardo jamás defendió una emancipación femenina que supusiera renunciar a esa vocación que consideraba connatural a la mujer.

El personaje titular de Geórgicas (PARDO BAZÁN, 1990 .T.I), nos brinda otro ejemplo de mujer fuerte y natural. Aura Lebriña será la encargada de devolver el honor a su familia. El asesinato de su hermano Andrés a manos de la odiosa familia Raposo será vengado por la muchacha. Doña Emilia hace, sin embargo, puntual referencia a que el comportamiento de Aura es del todo masculino. Esto es, la joven Lebriña actúa de esa manera porque fue ella la que he- 
redó la virilidad de la familia. Así pues, estamos ante el eterno dilema. La mujer fuerte en los relatos de la Condesa tiene características y actitudes de hombre. En resumen, la fuerza y el carácter son cualidades típicamente masculinas; el apocamiento y la debilidad, son defectos femeninos. En ocasiones, las cosas cambian... y son las mujeres las que poseen esas virtudes tan admiradas.

Sin embargo, había alguien que no olvidaba al que se pudría bajo la cruz negra del cementerio: Aura, la hermana, la que se había llevado toda la virilidad de la familia. Vestida de luto, en pie en el umbral de su casucha, ronca a fuerza de llorar, lanzaba a la casa de los Raposo ardientes miradas de reto y maldición. Y sucedió que al verano siguiente, cuando la cosecha recogida ya prometía abundancia, una noche sin saber por qué, prendióse fuego el pajar de Raposo y a la vez ardieron el cobertizo, el hórreo y la vivienda. Los Raposo, aunque dormían como marmotas, al descubrirse el fuego, pudieron salvar, sufriendo graves quemaduras sólo a uno de sus hijos. A Román, el que pasaba por ser el autor material de la muerte de Andrés Lebriña, se le encontró carbonizado sin que nadie comprendiese cómo un mozo tan ágil no supo librarse del incendio. Geórgicas: 218.

Del mismo estilo que las anteriores es el personaje de La Camarona (HILLS, 1997: 179-180). Si la Mayorazga es feliz en las montañas, la Camarona prefiere el mar. Posee una capacidad física extraordinaria y reemplaza a sus hermanos cuando dejan la casa familiar. Para ella el mar es su vida y no hay nada en el mundo que pueda reemplazar su apego a ese tipo de vida. Así pues, cuando la codicia de sus padres decide casarla con un hombre que no ama, ella se niega. Ante la insistencia de los padres, la Camarona accede, pero elige ella el partido. Se trata de un marinero sin recursos, curtido por el aire marino, con quien vive sin alejarse del amado mar. Este matrimonio goza de una vida alegre y, de nuevo, el embarazo viene a colmar la felicidad y el contento.

Es interesante resaltar la forma de vida de estas mujeres. Por un lado, llevan una vida masculina, con lo que resaltan y enaltecen el orden patriarcal; por otra, gozan de una libertad envidiable. Finalmente, logran la felicidad plena haciéndose madres. Es de tener en cuenta esto último, por si esta circunstancia nos da idea del ideal feminista que preconizaba la Condesa.

Las preocupaciones feministas de Pardo Bazán giran alrededor de dos arquetipos: la mujer con complejo de culpabilidad -que le sirve para criticar la injusticia del sistema patriarcal-, y la mujer fuerte. Ann K. Hills se pregunta qué efecto tendrían en la sociedad del momento los relatos que erigen a la campesina gallega como imagen primordial (HILLS, 1997: 180). Tal vez la consideraran una figura arraigada en el folclore y no supieran ver el trasfondo. Sea 
como fuere, una cosa es cierta, doña Emilia se puso a indagar en la psicología femenina y creemos que con éxito. Sus relatos cortos son mucho más comprometidos y progresistas —en relación al tema femenino- que sus novelas largas. El papel que desempeñó la Condesa fue impresionante. Debemos tener en cuenta que el feminismo español en el XIX es poco menos que inexistente. La sociedad no puede dar crédito a un movimiento tan desestabilizador como el feminismo, que con su sola presencia removería cimientos y la base natural del sistema, esto es, la familia.

Desde todas las facciones políticas, la mujer era considerada la compañera del hombre. Su misión social era servirle de apoyo y ocuparse de su descendencia. Una visión de la mujer como ser independiente se hacía demasiado conflictiva. A este respecto, doña Emilia plantea en su cuentística el problema de la situación femenina. Por regla general, sus personajes femeninos representan a mujeres maltratadas o a mujeres apegadas al ROL tradicional. En otras ocasiones y siempre supeditadas a determinados lugares, sus féminas poseen una personalidad fuera de lo común (La Mayorazga...). Pero no es habitual y tampoco sabemos si la Condesa recomendaría esa línea de actuación. En sus relatos, lo común es la mujer encerrada, la que está bajo sospecha, la acosada por los malos tratos y calumniada vilmente por el poder patriarcal. Toda aquella que se sale de la norma queda marcada para siempre. La cuentística de la Pardo está llena de relatos en donde el hombre sospecha de la mujer y, o bien la maltrata física o psicológicamente, o se hunde él mismo. Uno de los relatos más significativos e increíbles lo constituye La careta rosa (PARDO BAZÁN, 1990, T.IV). Todo gira en torno al descubrimiento que la hija de un matrimonio muy feliz y dichoso hace de una careta rosa. La descubre curioseando entre los cachivaches de la madre. El hallazgo tortura al padre de tal forma que enloquece de celos. No lo entiende. El origen de la careta le hace sospechar un posible disfrute que desconocía y del que él no tomó parte.

Pero jamás lograría arrancar a su mujer la confesión plena, clara, leal. No, sin duda lo de la careta era algo inconfesable, sabe Dios qué ... Algo que hacía palidecer el rostro, que ya siempre se había de figurar tapado con el raso de la careta que no palidece. La careta rosa: 29-30.

Como hemos apreciado en La flor seca, el varón desea controlar por todos los medios la vida de la mujer. La necesidad de los hombres de controlar a las mujeres es muy antigua. En el hombre subyace un temor hacia la mujer que hace que desee controlarla y someterla. Doña Emilia aborda la cuestión en innumerables ocasiones, pues en muchos de sus relatos presenta al varón como un ser obsesionado con la idea del engaño. En Humano (PARDO BAZÁN, 1990, 
T.IV), el protagonista llega a la paranoia en su intento de descifrar si el cariño que le da su esposa es o no es verdadero:

... y estudió sin cesar si aquel cariño que su esposa le demostraba era o no verdadero. Ahí tiene usted un inconveniente de su irracionalidad: el can no se preocupa de la lealtad moral de su hembra, aunque se engarza a dentelladas con sus rivales en momentos críticos en que es lógico el derecho a perpetuar la especie. Humano: 125.

Doña Emilia advierte en el varón una serie de factores que, a su juicio, son los causantes de un posible sentimiento de envidia y temor hacia las mujeres. La Condesa señala la dificultad del varón para confirmar la paternidad del hijo como posible causa de ese comportamiento. El temor a sentirse bu 'ado subyace en el subconsciente de tal manera que a la mínima sospecha la reacción es violentísima.

Doña Emilia estuvo siempre a favor de que las mujeres trabajasen, de que fuesen útiles. En su opinión, el trabajo dignificaba a la mujer. En sus relatos y novelas alaba a aquellas mujeres que se ganan el sustento, pero no deja de criticar las condiciones en que muchas de ellas se encuentran. La figura de la mujer dedicada exclusivamente al cuidado del hogar y de su familia, predominante en las clases altas y acomodadas, no pudo sostenerse a medida que las clases medias cobraron fuerza. A partir de ese momento las mujeres de ese estrato social tuvieron que entrar a formar parte del engranaje social de la producción. Por ello, el poder patriarcal no tuvo más remedio que permitir que aprendieran lo que antes les había sido negado en aras de la pureza. Y es que una manera de protegerse de la mujer es castigarla y despreciar sus facultades. Al considerarla el ángel del hogar, al negarle la posihilidad de valerse por sí misma o al proporcionarle una ocupación en virtud de intereses productivos, la sociedad la menosprecia y ultraja. El homr a niega las cualidades de la mujer calificando sus ventajas como desventajas e invirtiendo sus aciertos de propiedades malignas y misteriosas.

La creencia de que la mujer tiene una esencia interior que se desarrolla en la pasividad sexual, el sometimienti: al varón y la consagración amorosa a la crianza de los hijos constituía la vieja definición de lo femenino, es decir, aquello que es característico y que individualiza a la mujer. Pues bien, esa mística de la feminidad aparece también reflejada en los cuentos de doña Emilia, aunque ella, fiel a su estilo, impone una cierta rebeldía al perpetuo sometimiento de la mujer. La perfecta casada, saturada del batallar doméstico al que se entregaba con la abnegación que le habían enseñado Fantaseando (PARDO BAZÁN, 1990, T.IV), se cambiaría gozosa por la cupletista bonita que tantos 
aplausos recoge. Sin embargo, sólo le está permitido mirar el jardín florido. La sociedad patriarcal impone sus leyes y éstas señalan que la mujer ha de ser el espejo del hombre. Su labor es la de ser mediadora y vivir para los demás.

Cuando la Condesa escribe, su escritura significa una liberación. Doña Emilia sabía que la escritura femenina se amoldaba obligatoriamente a la estructura de la sociedad. Era consciente que dicha escritura había sufrido serias transformaciones, pasando del murmullo apenas perceptible a la protesta airada. Nuestra escritora escribe para esconder su rabia. La situación de la mujer intelectual llegó a preocuparla seriamente, pues ella misma padeció las consecuencias. De ahí que, a pesar de las contradicciones que suscita su obra literaria, creemos que el grito, la protesta o en ocasiones el murmullo feminista están siempre presentes. La Pardo concebía la escritura como arte, con independencia del sexo del autor. Aunque es consciente de que a muchas escritoras les falta «oficio», no por ello negaba la capacidad de evolución. Criticó abiertamente a quienes daban por hecho que la mujer carecía de facultad creadora. La supuesta inferioridad creativa de la mujer se debía a su situación social; relegada siempre a la sombra del razonar masculino, no ha tenido tiempo de desarrollarse.

Los relatos cortos de la Condesa proponen una división del carácter femenino en dos puntos fundamentales: uno, en donde la mujer acepta su papel en la sociedad tal y como la tradición lo exige; otro, en donde la mujer se declara en rebeldía. En relación al primero, nuestra autora echa la culpa al varón que acostumbra a encerrar a las mujeres con el ánimo de protegerlas. El segundo, de inspiración claramente feminista, presenta a una mujer que polemiza con su destino y desaira a la sociedad ${ }^{3}$. Esto último representa a la Emilia más auténtica.

Doña Emilia retrató con habilidad el complejo mundo de las relaciones de pareja. Las mujeres enérgicas, las dóciles, los matrimonios desiguales, el triste porvenir de las damas de clase media, el abuso de poder por parte del hombre ..., todo ello, visto con ojo crítico y lucidez característica. Sin duda, el personaje más apreciado por nuestra escritora es el de la hembra con carácter y decisión. Las mujeres dóciles también aparecen en sus cuentos. Con frecuencia, nuestra autora repara en su situación al lado de un marido que las maltrata. Suelen ser criaturas pusilánimes, dignas de lástima y compasión. De cualquier forma, hay en to-

3 Ciplijauskaité, Biruté. La novela femenina contemporánea (1970-1985): Hacia una tipología de la narración en primera persona. Barcelona. Anthropos, 1. ${ }^{a}$ edición, 1994, p. 15. La autora señala la división de Elaine Showalter con respecto a la novela inglesa del siglo XIX : femenina, feminista y de mujer. Hemos asimilado, no sin cautela, las dos primeras en relación a la obra de doña Emilia. 
da la cuentística de doña Emilia una constante: el hincapié en el comportamiento del varón. La mayoría de los personajes masculinos que aparecen en sus relatos son seres mezquinos, que no contentos con aprovecharse de la libertad de movimientos que la sociedad les brinda, cometen la bajeza de humillar a sus mujeres. Doña Emilia critica la conveniencia y el interés que despierta en muchos hombres la codicia de disfrutar de una cómoda posición social. Aunque con frecuencia muestre el lado más oscuro de la personalidad masculina, lo cierto es que tampoco las damas se libran de su escrutadora mirada. En especial, las señoritas de la burguesía que son criticadas duramente por querer aparentar lo que no son. Al final, su situación se resume casi siempre en un triste drama.

Como podemos observar, una de las preocupaciones de la Condesa fueron las relaciones de pareja. Nuestra autora era consciente de que ahí estaba la base de todo. Ella pretende partir de la armonía, del misterio, del pudor y de la pasión para conseguir la felicidad. Lo contrario le sugiere un espectáculo grotesco. Sus cuentos dan buena prueba de ello.

\section{REFERENCIAS BIBLIOGRÁFICAS}

Blanco, Carmen (1991): Literatura galega da muller. Vigo, Xerais.

CIPLIJAUSKAITÉ. BIRUTÉ (1984): La mujer insatisfecha. Barcelona, Edhasa.

CIPLIJAUSKAITÉ. BIRUTÉ (1994): La novela femenina contemporánea (1970-1985).

Barcelona, Anthropos.

González Arias, FrancisCa (1997): «La poética de Galicia en los cuentos de Emi-

lia Pardo Bazán» en Estudios sobre Emilia Pardo Bazán. IN MEMORIAM MAURICE HEMINGWAY. Universidad de Santiago de Compostela, 147-169. HILls. Ann K. (1997): «Dos arquetipos femeninos en los cuentos de Emilia Pardo-

Bazán», Romance Quartely, 44/3, 171-180.

LAFFITTE, MARÍa (1964): La mujer en España: cien años de historia, 1860-1960. Madrid, Aguilar.

MoI, TORIL (1995): Teoría literaria feminista . Madrid, Cátedra.

PARdo BAZÁn, Emilia (1975): Un destripador de antaño y otros relatos. Madrid, Alianza Editorial-Real Academia Gallega.

- (1990): Cuentos completos, La Coruña. Fundación. BARRIÉ dE LA MAZA Conde de Fenosa, Galicia Editorial. Edición de Juan Paredes Núñez. Tomos I, II, III, y IV.

- (1996): Un destripador de antaño y otros relatos. Madrid, Aguilar.

WOOLF. VIRGINIA (1981): Las mujeres y la literatura. Barcelona, Lumen. 